\title{
The arbuscular mycorrhizal fungi colonizing the roots of pre-nursery stage of oil palm seedlings: Elaeis guineensis in Malaysia
}

\author{
Khor Yen Yen and Rosnida Tajuddin ${ }^{\star}$ \\ School of Biological Sciences, Universiti Sains Malaysia, 11800 Minden, Pulau Pinang, Malaysia. \\ Email: rosnidatajuddin@usm.my, rosnidatajuddin@yahoo.com
}

Received 2 February 2018; Received in revised form 30 October 2018; Accepted 31 October 2018

\begin{abstract}
Aims: Arbuscular mycorrhizal is an obligate mutualistic symbiosis fungus which survives by forming endomycorrhizal on plant roots. The arbuscular mycorrhizal fungi are not host-specific, allowing them to form a mutualistic symbiosis with a wide range of host plants including oil palm. In Malaysia, the arbuscular mycorrhizal fungi are used as a growth enhancer for the oil palm: Elaeis guineensis. The arbuscular mycorrhizal fungi are introduced only during transplantation to the field when the ages of the seedlings are approximately one year old. As such, this study is designed to investigate the ability of the arbuscular mycorrhizal fungi to form colonisation with pre-nursery oil palm seedlings.

Methodology and results: Here, the arbuscular mycorrhizal fungi were introduced at the pre-nursery stage oil palm seedlings. After inoculation, the seedlings were harvested on different days, i.e. on day-3, day-7, day-14, day-21, day-40 and day- 60 to determine the colonisation of arbuscular mycorrhizal fungi. We found that the arbuscular mycorrhizal fungi are able to form a mycorrhizal association with the oil palm seedling at the pre-nursery stage after 40 days of inoculation, and the arbuscular mycorrhizal fungi that formed the association are Glomus sp. and Scutellospora sp. Conclusion, significance and impact of study: This study suggested that the oil palm seedling can be made into a mycorrhizal plant as early as the nursery stage before transplanting them into the plantation.
\end{abstract}

Keywords: Glomus sp., Scutellospora sp., arbuscular mycorrhiza, fertilizers, oil palm

\section{INTRODUCTION}

Oil palm plantations cover a large area in Malaysia and contribute as a major economic income of Malaysia (Lindsay et al., 2012). In particular, the development of oil palm plantations has helped alleviate poverty among landless farmers in Malaysia (Basiron, 2007). Palm oil is now a major source of sustainable and renewable raw material for the world's food, oleochemical and biofuel industries (Basiron, 2007). In addition, high expectation and demand for palm oil in biofuel research has strengthened the value of oil palm in the world's market (Koh, 2007). In order to focus on developing a sustainable country, the oil palm plantations in Malaysia should not only aim at improving the yield of the oil palm but also focus on the long-lived land usage for agriculture (Basiron, 2007). The arbuscular mycorrhizal (AM) fungi have played the vital role of creating an ideal ecological agriculture and also fulfilling the quantity and quality demands from the public (Smith and Read, 2008). The symbiosis of AM fungi and plant has existed for a long time and it is believed that the evolution and diversity of plant kingdom are highly related to the colonisation of AM fungi on plant root (Smith and Read, 2008). This is a mutual symbiosis in which both the AM fungi and host plant benefit from each other (Peterson et al., 2004; Smith et al., 2011). This symbiosis confers benefits directly to the host plant's growth and development through the acquisition of phosphorus $(P)$ and other mineral nutrients from the soil via the AM pathway (Harrier, 2001; Aggarwal et al., 2011). In this symbiosis relationship, the AM fungi receive energy supplies in the form of carbon from its host plant (Ibijbijen et al., 1996). The AM fungi can increase the tolerance ability of the host plant towards environmental stresses such as toxicity, drought condition and high salinity (Smith and Read, 2008).

The root structure of the oil palm shows a high association with AM fungi to obtain nutrients (Corley and Tinker, 2015). Most of the oil palm plantation owners apply an enormous dosage of fertiliser to increase the yield of palm oil (Smith and Read, 2008). In fact, without the aid of the AM fungi, the amount of nutrient absorption by oil palm is reduced (Corley and Tinker, 2015). Consequently, the excess fertiliser will be washed out and cause environmental problems such as eutrophication (Tilman et al., 2002). In order to reduce the cost of a plantation to gain the highest profit, we should utilise natural beneficial fungi, i.e. the AM fungi to promote our 
agriculture industry (Smith and Read, 2008). One of the current practices conducted by some planters is the introduction of AM fungi to oil palms during the transplantation process of the palms to the plantation. As such, this study is designed to investigate the ability of pre-mature oil palm seedling to form a mycorrhizal association with $A M$ fungi isolated from oil palm plantation, which will allow the planters to transplant 'ready-mycorrhizal' oil palm seedling to the plantation in the future. The stage of nursery seedling is more vulnerable but important to ensure good development and yield of the plant (Azcón-Aguilar and Barea, 1997).

\section{MATERIALS AND METHODS}

\section{Soil sampling}

The soil samples were collected from Sungai Kechil Ulu Bandar Baharu oil palm plantation, Perak, Malaysia (N05 06 '33.9" $\mathrm{E} 100^{\circ} 32^{\prime} 45.9^{\prime \prime}$ ) and the oil palms ages were three years old. This plantation is an open plantation area with good aeration.

\section{Isolation of arbuscular mycorrhizal fungi spores}

The wet-sieving technique was used to isolate the AM from soil samples as per Brundrett et al. (1996). The 100 $\mathrm{g}$ of soil was weighed and mixed thoroughly with water. The soil was then sieved through multiple sizes of sieves, starting with $1,000 \mu \mathrm{m}, 500 \mu \mathrm{m}, 250 \mu \mathrm{m}, 75 \mu \mathrm{m}$ and followed by $45 \mu \mathrm{m}$. The debris that had been sieved in $1,000 \mu \mathrm{m}$ and $500 \mu \mathrm{m}$ sieves were thrown away and the soil samples that were sieved using the $250 \mu \mathrm{m}, 75 \mu \mathrm{m}$ and $45 \mu \mathrm{m}$ sieves were collected into $50 \mathrm{~mL}$ centrifugation tubes for centrifugation process. The samples were centrifuged for $3 \mathrm{~min}$ at 2,000 rotations per minute (rpm) to separate the spore from the soil samples. The floating debris with supernatant was discarded and the pellets were kept for the second centrifugation. The pellets were re-suspended in $50 \%$ sucrose and second centrifugation was conducted for $1 \mathrm{~min}$ at 2,000 rpm. A vacuum pump was used to filter the supernatant with a Whatman No. 42 filter paper. The spore observation was then conducted under the dissecting microscope. The spores were sorted out by their shapes, sizes and colour under the dissecting microscope. The different morphologies of the AM spores were selected and made into slides and the pictures were taken using camera Olympus BX41 attached to the compound microscope equipped with the software Cell $A$. The spores were identified based on their physical morphologies.

\section{Arbuscular mycorrhiza propagation}

Pot cultures with six pots of three months old oil palm nursery seedling were used to propagate the AM spores. The isolated AM spores were washed from the filter paper into the pot using distilled water. The three months old oil palm nursery seedlings were then left for two months to allow the AM spores to propagate.

\section{Sowing the oil palm seedlings.}

The oil palm seeds were sowed in heat-sterilised soil (150 ${ }^{\circ} \mathrm{C}$ for $24 \mathrm{~h}$ ) with $4: 1$ of clay : sand ratio that were mixed together thoroughly. The mixed sterilised soil was filled into the seed tray tightly to prevent the soil leakage from seed tray. While filling in the soils, the soils were watered to increase the soil compaction. The soil was added into the seed tray up to $80 \%$ full. A hole of $2 \mathrm{~cm}$ depth was made on each container soil and the seeds were sowed into the hole. The radical of the seed was ensured to be directed down and the plumule of seed was directed upward and covered with the soil. The seeds were left for approximately two months to grow into pre-nursery seedlings. The pre-nursery seedlings are the seedlings that are less than 3 months old, while the main nursery seedlings are the seedlings that are between 3 to 4 months old (Yusoff et al., 2013).

\section{Preparation of the arbuscular mycorrhizal fungi inoculums}

After three months of AM spores propagation in the pots of three months old oil palm seedlings (as section 2.4), the oil palm seedlings were harvested to be made into the AM inoculums. Enumeration of spores was conducted to ensure the success of propagation. The host plants were harvested and the number of spores was calculated. The soils from three pots of host plants were mixed together and the roots of the propagation AM spores host were chopped into small pieces and mixed into the entire propagated soil.

\section{Transplantation and inoculation of arbuscular mycorrhizal fungi}

Ninety pre-nursery seedlings were transferred into $15 \mathrm{~cm}$ $\times 23 \mathrm{~cm}$ (6 inch $\times 9$ inch) polybags after two months of germination in a mixture oven-sterilised soil of clay, sand and organic soil in the ratio of 4 clay : 1 sand : 1 organic soil. During the transplantation, $100 \mathrm{~g}$ of inoculum soil had been weighed and added into 45 pots of oil palm seedlings. Another 45 oil palm seedlings were potted as controlled pots with no inoculums soils added. The seedlings were harvested on different days, i.e. on day-3, day-7, day-14, day-21 and day-40 after the introduction of AM inoculums.

\section{Roots staining}

The harvested roots were cut and immersed in $10 \% \mathrm{KOH}$ $(\mathrm{w} / \mathrm{v})$ at $90{ }^{\circ} \mathrm{C}$ for $2-3 \mathrm{~h}$ in a water bath using a modified method from Phillips and Hayman (1970). KOH in the staining functions as the bleaching agent to remove dark pigments on the root surface in order to ease the staining process (Phillips and Hayman, 1970). The roots were then acidified in $5 \% \mathrm{HCl}$ prior to the staining as the $\mathrm{HCL}$ will neutralise the alkaline of the bleached roots (GalindoCastañeda and Romero, 2013). The roots were stained in $0.05 \% \mathrm{w} / \mathrm{v}$ trypan blue in lactoglycerol in a $90{ }^{\circ} \mathrm{C}$ water 
bath for 12 to $60 \mathrm{~min}$ (Bevege, 1968; Phillips and Hayman, 1970; Brundrett et al., 1996) for root colouration. The stained roots were stored in $50 \%$ glycerol before observation, as recommended by Brundrett et al. (1996).

\section{RESULTS}

\section{Identification of arbuscular mycorrhizal fungi spores}

Figure 1 shows the fresh Glomus sp. spores with aggregated spore arrangement under a dissecting microscope. The Glomus sp. spores have attached to the subtending hyphae and showed no cell wall (Figure 1c1f). Under the compound microscope, the structure of the subtending hyphae is simpler (Figure 1e) in comparison to the swollen subtending as Scutellospora sp. and Gigaspora sp. The Glomus sp. spores showed the colour of 60:50:80 CYM (Cyan:Yellow:Magenta) value as suggested by International Culture Collection of (Vesicular) Arbuscular Mycorrhizal Fungi (INVAM) colour chart designed by Morton (1992).

Figure 2 shows the isolated fresh Scutellospora sp. spore and the squashed Scutellospora sp. spore under a dissecting microscope and a compound microscope, respectively. The fresh Scutellospora sp. spore was attached to a swollen subtending hypha. The
Scutellospora sp. spore showed singly spore aggregation. The squashed Scutellospora sp. spore showed two layers of cell walls, i.e. the inner wall and outer wall. The germination shield was seen in the squashed Scutellospora sp. spore. The Glomus sp. spores showed a colour of 20:70:80 CYM (Cyan:Yellow:Magenta) value according to the INVAM colour chart designed by Morton (1992).

\section{Colonisation of arbuscular mycorrhizal fungi in pre- nursery oil palm roots and development of arbuscular mycorrhizas on oil palm roots}

The AM-treated oil palm seedlings were harvested on various days to observe the development of AM colonisation on oil palm. Figure $3 a-x$ show the development of AM morphologically. After 3 days of AM introduction, there was no sign or symptom of colonisation by AM fungi on the seedling roots showed in Figure $3 a$ and $b$. The stained secondary and tertiary roots did not show any sign of colonisation and the plant cells had no hyphal infection.

For oil palm seedlings harvested after 7 days, there were signs of colonisation of AM fungi as shown in Figure $3 \mathrm{c}$ and $\mathrm{d}$.

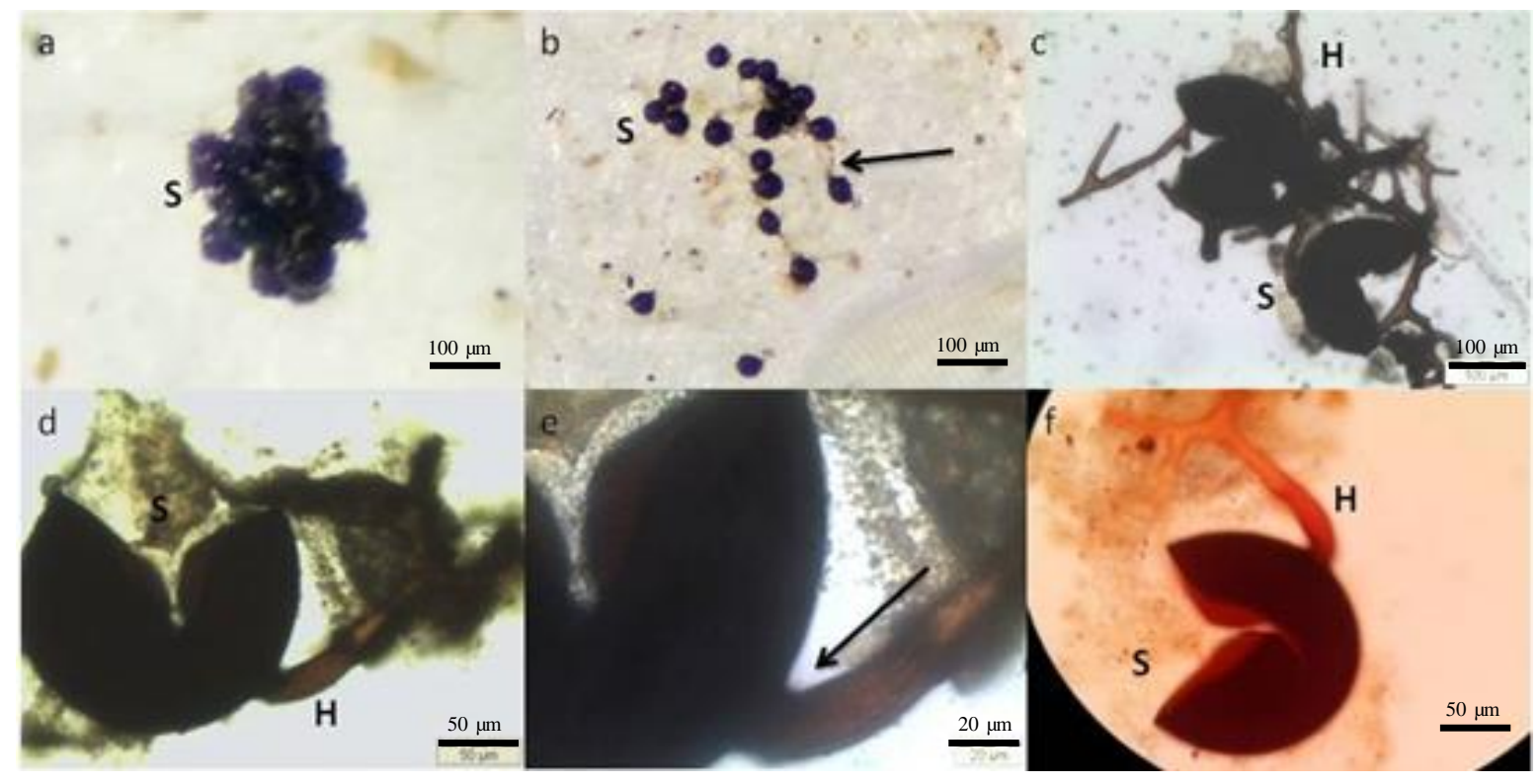

Figure 1: The Glomus sp. spores isolated from the sampled soil. (a and b) The fresh and unsquash Glomus sp. spores observed under dissecting microscope. (c, d and e) The squashed Glomus sp. spores observed under compound microscope. (a) The fresh Glomus sp. spores with aggregated spore arrangement. (b) Each of the separated fresh spores are attached to the subtending hyphae (arrow). (c) The squashed spores attached to each other and formed aggregation arrangement. (d) The squashed Glomus sp. spore attached subtending hypae. (e) Simple subtending hyphae attached with Glomus sp. spore. (f) The Glomus sp. spores showed the colour of 60:50:80 CYM value. S, spore; $\mathrm{H}$, hyphae. 


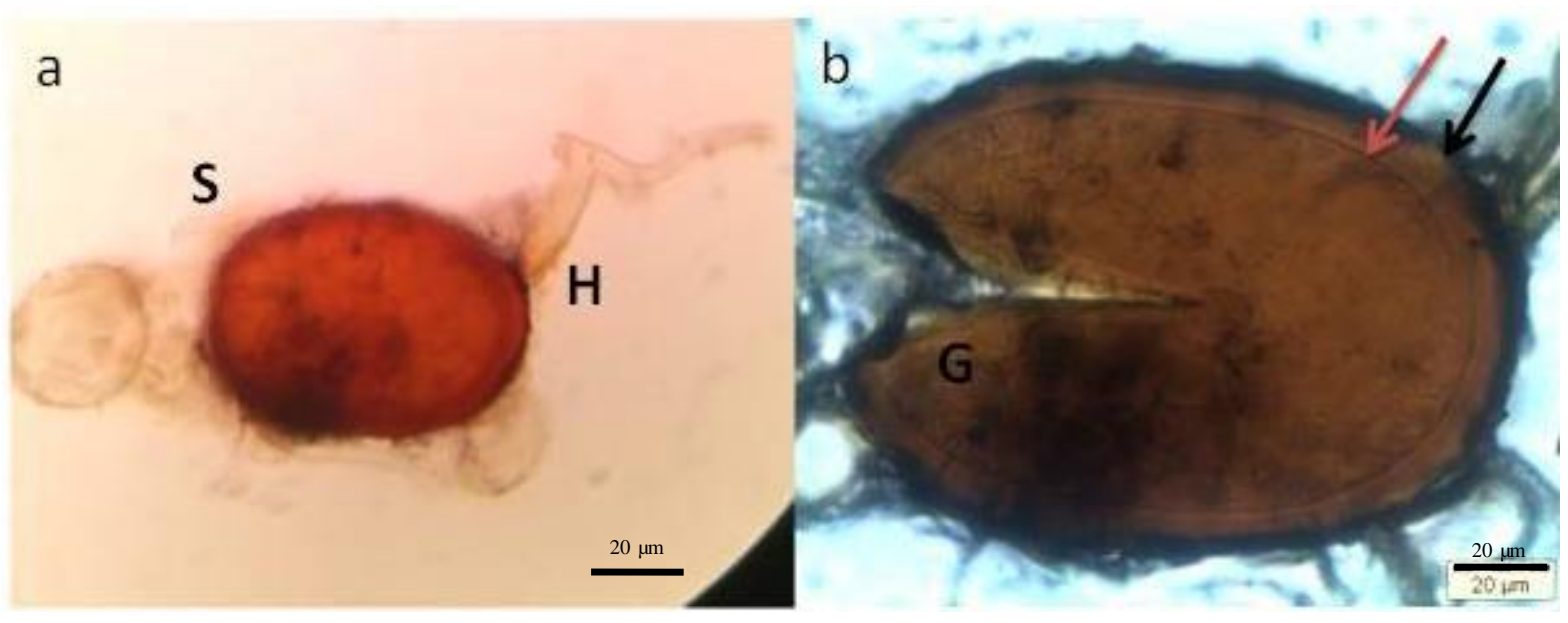

Figure 2: The Scutellospora sp. spore. (a) The fresh Scutellospora spore attached to a swollen subtending hypha. (b) The squashed spore showing its inner wall (red arrow), outer wall (black arrow) and germination shield. S, spore; H, hyphae; G, germination shield. The Scutellospora sp. spores showed a colour of 20:70:80 CYM value.

The hyphae development was depicted by the blue stain in Figure 3c. The hyphae can be differentiated from the secondary and tertiary roots cell given that trypan blue will only stain the fungi structures (Phillips and Hayman, 1970). Figure 3d shows a seedling with an extraradical hyphal network. The development of AM fungi in 14 days is as shown in Figure $3 e$ and $\mathrm{f}$. The intraradical hyphal network developed from an entry point in the exodermis cell is shown in Figure $3 e$. Figure $3 f$ shows the appressorium as the initial fungal penetration on a host plant.

Figure $3 \mathrm{~g}$ shows the stable colonisation of AM given the various types of the hyphal network formed in the plant cells after 21 days of AM introduction into oil palm seedlings. Figure 3h-k show the infection started by the appressorium of $\mathrm{AM}$ fungus and the formation of entry points. The entry points grew and branched into intraradical hyphae in the exodermis cells and cortex cells. Figure 1.3l shows the extraradical and intraradical hyphal network which grew densely and compactly by surrounding the tertiary roots for further infection.

Figure $3 \mathrm{~m}-\mathrm{o}$ show the various sizes and huge numbers of vesicles developed in plant cells from the oil palm seedlings harvested after 40 days of AM introduction. The vesicles had been stained and attached with hyphae. Figure $3 n$ shows that the vesicles were connected to each other through the hyphal network. Figure 30 shows that the vesicles grew extracellularly between the plant cells. The thickened wall of vesicles is a typical structure of Glomus sp.

Figure $3 p-x$ show the formation of arbuscules observed in the oil palm seedlings harvested after 60 days. There were symptoms of two species of AM fungi, i.e. the Scutellospora sp. and Glomus sp. The hyphae of Scutellospora sp. is thick and is stained dark in Figure 3r. The hyphae grew intercellularly, entered the cell and formed intracellular looping hyphae. The arbuscules appeared wispy due to the curving hyphae as shown in Figure 3s. Based on these characteristics, the AM fungal species is suspected to be Scutellospora sp. based on Figure $3 r$ and $s$. The arbuscules formation was highly branched and compact in the plant cells as shown in Figure 3t-x. The arbuscules was branched from the intercellular hyphal network.

The mature arbuscules showed trunk which developed from intercellular hyphae as shown in Figure $3 x$. Also, the hyphae grew by densely surrounding the inside and outside of the plant cells as shown in Figure 3tw. The parallel spread of intercellular hyphae resulted in a linear appearance of the AM hyphae. The linear (Arum) series of AM showed hyphae proliferation by growing longitudinally between the intercellular airspace of a host plant cells as shown in Figure $3 u$. Based on these characteristics, the AM fungal species is suspected to be Glomus sp.

\section{DISCUSSION}

There are two genera of AM fungi collected and isolated from the field soils, i.e.the Glomus and the Scutellospora. The genus Glomus is the dominant AM fungi found in most of the host plants. A study showed that the Glomus $\mathrm{sp}$. was the most frequently occurring AM fungi species found in the rhizosphere of the potential commercial tree species, Octomeles sumatrana and Anthocephalus chinensis in Niah, Sarawak (Chubo et al., 2009). Spore identification was done in reference to Brundrett et al. (1996). There are many morphological aspects that can be used to identify the AM spores. In this project, the sporulant arrangement, subtending hyphae, the wall layer and the colour of the spores were considered during the spore identification. The spore colour value had been determined in reference to the modified version of the INVAM colour chat by Morton (1992). 
Malays. J. Microbiol. Vol 15(1) 2019, pp. 52-59

DOI: http://dx.doi.org/10.21161/mjm.117517

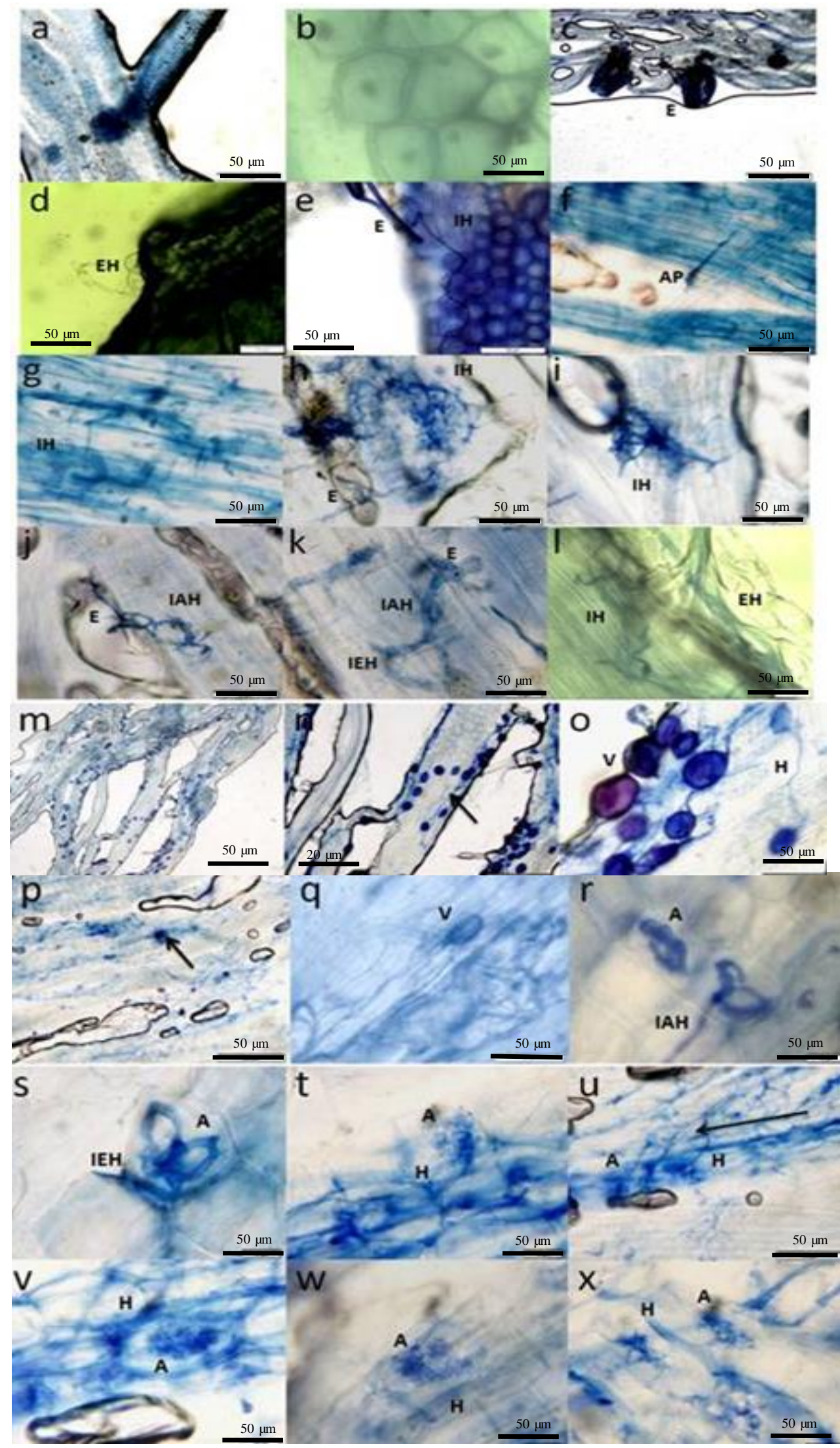


Figure 3: Colonisation of arbuscular mycorrhizal fungi in pre-nursery oil palm roots. (a and b) After 3 days of AM introduction into oil palm seedlings. (c and d) After 7 days of AM introduction into oil palm seedlings. (e and f) After 14 days of AM introduction into oil palm seedlings. ( $\mathrm{g}-\mathrm{l})$ After 21 days of $A M$ introduction into oil palm seedlings. (m-o) After 40 days of AM introduction into oil palm seedlings. ( $p-x)$ After 60 days of AM introduction into oil palm seedlings. (a) Secondary and tertiary roots without colonisation point. (b) Clear plant cell without staining effect. (c) Secondary and tertiary roots with a staining effect. (d) Seedling with an extraradical hyphal network. (e) Intraradical hyphal network development from an entry point in exodermis cell. (f) Appressorium as the initial fungal penetration on a host plant. (g) Various types of hyphal network formed in plant cells. (h) Dense intraradical hyphal network formed via the entry point in cortex cell. (i) Intraradical network developed from the main hyphae. (j) Intracellular hyphae developed from the entry point. (k) Hyphae developed from the entry point to form intracellular hyphae and extracellular hyphae. (I) Strong and dense extraradical and intraradical hyphal network formed in tertiary roots. (m-o) Various sizes and huge numbers of vesicles shown under different magnifications of a compound microscope. Each vesicle attached with hyphae and connected each other with a hyphal network (arrow). (o) Vesicles grew extracellularly and the vesicles had thickened wall (arrow). (p) Formation of arbuscules (arrow). (q) A few vesicles. ( $r-s)$ Scutellospora sp. arbuscules. (r) Thick looping hyphae grew intracellularly and wispy arbuscules formed in the cells. (s) Extracellular hyphae grew in the plant cell and formed looped and wispy arbuscules. (t-x) Glomus sp. Arbuscules. (t-w) Dense hyphal surrounded in and out of the plant cells and compact fine branch hyphae formed arbuscules in the plant cells. (u) A parallel spread of intercellular hyphae resulting in a linear (Arum) appearance of the AM hyphae (arrow). ( $\mathrm{x}$ ) Mature arbuscules showing trunk which developed from intercellular hyphae. AP, appresorium; $E$, entry point; $H$, hyphae; $E H$, extraradical hyphae; $I H$, intraradical hyphae; IAH, intracellular hyphae; IEH, intercellular hyphae; T, trunk; V, vesicle; A, arbuscules.

Figure 1a and $\mathrm{c}$ show the fresh spores and the squashed spores forming sporulate aggregation. The sporulate aggregation is one of the characteristics of Glomus sp. spores and the spore arrangement is normally found in the field soil. This is because the Glomus sp. spores need to accumulate sufficien energy to form the aggregation (Brundrett et al., 1996). Besides, the identification was done based on the hyphae attachment of spores. The subtending hypha of Glomus sp. spores was attached in a simple way, in contrast to the bulbous subtending hyphae in Gigaspora spore and Scutellospora spore.

In Figure 2, the characteristics of Scutellospora spores were observed. The spore arrangement is totally different from the Glomus spore in which the Scutellospora spore appear singly and has no sporulant aggregation. The subtending hyphae of Scutellospora spore are swollen or bulbous, similar to Gigaspora. However, the germination shield showed in Figure $2 \mathrm{~b}$ show the difference between Scutellospora and Gigaspora, i.e.the germination shield is not present in the Gigaspora sp. spore. The layered walls shown in Figure $2 \mathrm{~b}$ is also one of the characteristics of the Scutellaspora spores.

Besides that, the morphology of arbuscules can be used for AM fungi identification. The main arbuscular characteristics of Glomus sp. and Scutellaspora sp. are shown in Figure 3, which is in reference to Brundrett et al. (1996). However, the AM fungi are identified based on the morphology of the spores and arbuscules. To strengthen the evidence, a molecular test on AM spores should be done in further studies.

\section{Host plant physical response towards AM fungi colonisation}

In Figure $3 a$ and $b$, there was no colonisation sign of infection on the oil palm roots, indicating that the AM spore inoculums need more than three days to begin colonising the oil palm roots. The AM colonisation on oil palm roots initiated with the signs of a hyphal network from day-7 to day-60. The extraradical hyphal network developed first in AM colonisation as shown in Figure 3d, which is on day-7. A study conducted by GalindoCastañeda and Romero (2013) showed that the AM colonisation initiated with the evidence of the formation of an intraradical hyphal network take longer, approximately one month after planting the pre-nursery oil palm seedlings.

Although there were various types with an abundant of hyphal network colonised on the oil palm roots from day-7 until day-21 (Figure 3c-I), the signs of AM colonisation was not complete. Figure $3 \mathrm{l}$ and $\mathrm{m}$ show that the thick and high root mass are the obvious morphologies of a mycorrhizal root. These characteristics relate to the coevolution of the plant and the arbuscular mycorrhizae given that the thick and slow-growing dimorphic roots will maximise the colonisation of AM fungi on root cortex area (Brundrett, 2002).

\section{Interaction of AM fungi among the species}

In Figure 3m-o, the vesicles were abundant in the oil palm roots on day-40. In other words, the population of Glomus sp. was high. The sign of infection of Scutellospora sp. was not observed in the plant root on day-40 but the arbuscules were present in the day-60 oil palm seedling roots (Figure $3 r-s$ ). Figure $3 q$ shows the Glomus vesicles were weaker on day-60 relative to the 
vesicles on day-40. There was competition between Glomus sp. and Scutellospora sp. under a stress competition. Previously, Glomus sp. was the main AM fungi in day-40 oil palm roots, but the succession had been disturbed by the Scutellospora sp. The competition brings positive effects on AM fungi diversity in oil palm seedling roots. A study by Bever et al. (1996) showed that the different sporulation rate between the different $A M$ fungi creates a diverse AM fungi community within a host plant. A high diversity of AM fungi community constructs a diverse plant community structure (Vandenkoornhuyse et al., 2003).

\section{CONCLUSION}

This study showed that the arbuscular mycorrhizae was able to form colonisation on the pre-nursery oil palm seedling roots. The colonisation needs at least three days after inoculation to be initiated with an extraradical hyphal network formation. To achieve a stable colonisation, it needed less than 40 days of inoculation to develop the mycorrhizal association. Glomus sp. and Scutellospora $\mathrm{sp}$. had colonised the oil palm roots successfully. Various signs were formed on the oil palm roots as an indication of colonisation, i.e. the hyphae, vesicles and arbuscules. This study suggested that the oil palm seedling can be made into a mycorrhizal plant as early as the nursery stage before transplanting them into a plantation. As such, to enhance the plant growth and to strengthen the plant, it is suggested the arbuscular mycorrhizae should be applied at younger oil palm before transplanting the seedling into the field given the benefits of arbuscular mycorrhizae fungi to the plant.

\section{ACKNOWLEDGEMENTS}

We thank Prof Dr. Abu Hassan and Mr Abu Haimi for allowing us to conduct the sampling on their oil palm farms, School of Biological Sciences, Universiti Sains Malaysia for the laboratory facilities, and Universiti Sains Malaysia for the research grant. Financial support was provided by Universiti Sains Malaysia RUI Grant 1001/PBIOLOGI/811293 to Rosnida Tajuddin.

\section{REFERENCES}

Aggarwal, A., Kadian, N., Tanwar, A., Yadav, A. and Gupta, K. K. (2011). Role of arbuscular mycorrhizal fungi (AMF) in global sustainable development. Journal of Applied and Natural Science 3, 340-351.

Azcón-aguilar, C. and Barea, J. (1997). Applying mycorrhiza biotechnology to horticulture: Significance and potentials. Scientia Horticulturae 68, 1-24.

Basiron, Y. (2007). Palm oil production through sustainable plantations. European Journal of Lipid Science and Technology 109, 289-295.

Bevege, D. (1968). A rapid technique for clearing tannins and staining intact roots for detection of mycorrhizas caused by Endogone spp., and some records of infection in Australasian plants. Transactions of the British Mycological Society 51, 808-810.

Bever, J. D., Morton, J. B., Antonovics, J. And Schultz, P. A. (1996). Host-dependent sporulation and species diversity of arbuscular mycorrhizal fungi in a mown grassland. Journal of Ecology 84,71-82.

Brundrett, M., Bougher, N., Dell, B., Grove, T. and Malajczuk, N. (1996). Working with mycorrhizas in forestry and agriculture. Australian Centre for International Agricultural Research (ACIAR), Pirie Printers, Canberra, Australia 141-216.

Brundrett, M. C. (2002). Coevolution of roots and mycorrhizas of land plants. New Phytologist 154, 275304.

Chubo, J. K., Ong, K. H., Mardatin, N. F., Majid, N. A. and Muhamad, N. (2009). Genera of arbuscular mycorrhiza occurring within the rhizospheres of Octomeles sumatrana and Anthocephalus chinensis in Niah, Sarawak, Malaysia. ScienceAsia 35(4), 340345.

Corley, R. H. V. and Tinker, P. (2015). The oil palm (Fifith Edition). John Wiley \& Sons, Oxford, 1-239.

Galindo-Castañeda, T. and Romero, H. M. (2013). Mycorrhization in oil palm (Elaeis guineensis and $E$. oleifera $\times E$. guineensis) in the pre-nursery stage. Agronomía Colombiana 31, 95-102.

Harrier, L. (2001). The arbuscular mycorrhizal symbiosis: A molecular review of the fungal dimension. Journal of Experimental Botany 52, 469-478.

Ibijbijen, J., Urquiaga, S., Ismaili, M., Alves, B. and Boddey, R. (1996). Effect of arbuscular mycorrhizal fungi on growth, mineral nutrition and nitrogen fixation of three varieties of common beans (Phaseolus vulgaris). New Phytologist 134, 353-360.

Koh, L. P. (2007). Potential habitat and biodiversity losses from intensified biodiesel feedstock production. Conservation Biology 21, 1373-1375.

Lindsay, E., Convery, I., Ramsey, A. and Simmons, E. (2012). Changing place: Palm oil and sense of place in Borneo. Human Geographies - Journal of Studies and Research in Human Geographies 6, 45-53.

Morton, J. B. (1992). INVAM Newsletters. Volume 1-5. West Virginia University, Morgantown.

Peterson, R. L., Massicotte, H. B. and Melville, L. H. (2004). Mycorrhizas: Anatomy and cell biology. Wallingford, Oxon, UK. CABI Publication.

Phillips. J. and Hayman, D. (1970). Improved procedures for clearing roots and staining parasitic and vesicular-arbuscular mycorrhizal fungi for rapid assessment of infection. Transactions of the British Mycological Society 55, 158-161.

Smith, S. E., Jakobsen, I., Grønlund, M. and Smith, F. A. (2011). Roles of arbuscular mycorrhizas in plant phosphorus nutrition: Interactions between pathways of phosphorus uptake in arbuscular mycorrhizal roots have important implications for understanding and manipulating plant phosphorus acquisition. Plant Physiology 156, 1050-1057.

Smith, S. and Read, D. (2008). Mycorrhizal symbiosis (Third Edition). Academic Press, London. pp. 11-145. 
Malays. J. Microbiol. Vol 15(1) 2019, pp. 52-59

DOI: http://dx.doi.org/10.21161/mjm.117517

Tilman, D., Cassman, K. G., Matson, P. A, Naylor, R. and Polasky, S. (2002). Agricultural sustainability and intensive production practices. Nature 418, 671-677.

Vandenkoornhuyse, P., Ridgway, K., Watson, I., Fitter, A. and Young, J. (2003). Co-existing grass species have distinctive arbuscular mycorrhizal communities. Molecular Ecology 12, 3085-3095.

Yusoff, M. N., Ariffin, S. M., Chin, C. W. and Said, Z. M. (2013). Manual Pengurusan dan Amalan Baik Tapak Semaian Sawit. Felda Agricultural Services SDN. BHD, Kuala Lumpur, 14-31. 